\title{
FAMILIARES NA SALA DE ESPERA DE UMA UNIDADE DE TERAPIA INTENSIVA: sentimentos revelados ${ }^{\mathrm{a}}$
}

\author{
Gloriana F RIZON ${ }^{b}$, Eliane Regina Pereira do NASCIM ENT Oc, \\ Kátia Cilene G odinho BE RT ON CE L LO d, Josiane de Jesus M ART IN Se
}

\section{RESUM 0}

T rata-se de um estudo qualitativo que objetivou conhecer quais os sentimentos dos familiares de pacientes internados na U nidade de T erapia I ntensiva (UTI). 0 estudo foi real izado na UTI de um hospital geral de grande porte da região oeste de Santa Catarina. A coleta ocorreu em 2009, com entrevista semiestruturada a 18 familiares. Para o tratamento dos dados utilizou-se o D iscurso do Sujeito Coletivo. D os relatos surgiram dois temas relacionados aos sentimentos: à hospital ização na UTI e os durante a espera para entrar na unidade. A análise revel ou sentimentos como: dor, angústia, tristeza, impotência, medo, desespero, ansiedade e expectativa infinita. Espera-se que esses resultados possam auxiliar na capacitação dos profissionais, para o acolhimento à família e para a inser ção desta no ambiente da UTI, como el emento a ser integrado no cuidado de enfer magem, através de ações acolhedoras, ajudando-os a enfrentarem a hospitalização de um familiar na unidade crítica.

D escritores: U nidades de terapia intensiva. Família. E moções. E nfermagem familiar.

\section{RESUMEN}

Se trata de un estudio cualitativo que tuvo como objetivo comprender cuáles son los sentimientos de los familiares de pacientes ingresados en la U nidad de Cuidados Intensivos (U Cl). E I estudio se llevó a cabo en la U CI de un gran hospital general en la región oeste de Santa Catarina. L os datos fueron recolectados en el 2009 con una entrevista semi estructurada a las familias de dieciocho años. Para el tratamiento de datos fue utilizado el discurso del sujeto col ectivo. L os informes surgieron de dos elementos relacionados con los sentimientos: la hospitalización en la U Cl y durantela espera para entrar a la unidad. E I análisis reveló sentimientos como el dol or, la angustia, tristeza, impotencia, miedo, desesperación, ansiedad y expectativa infinita. Se espera que estos resultados puedan ayudar en la formación de los profesionales, a la familia de acogida y su inserción en el entorno de la U Cl como un elemento para ser integrados en los cuidados de enfermería, a través de acciones de bienvenida, ayudándoles a hacer frente a la hospitalización de un familiar en una unidad de críticos.

Descriptores: U nidad deterapia intensiva. Familia. E mociones. Enfermería dela familia.

T ítulo: F amília en la espera de una unidade de cuidados intensivos: sentimientos revelados.

\section{ABST RACT}

This is a qual itative study that aims to understand the feelings of relatives of patients admitted to the Intensive Care U nit (ICU ). T he study was conducted in the ICU of a large general hospital in the western region of Santa Catarina. T he data collection occur red in 2009 with a semi structured interview to eighteen families. F or data treatment the collective subject discourse was used. R eports emerged of tw 0 items related to feelings: hospitalization in the ICU and while waiting to enter the unit. T he anal ysis reveal ed feelings as pain, anguish, sadness, hel plessness, fear, despair, anxi ety and expectation infinite It is hoped that these results may assist in the training of professionals, to host the family and its insertion in the ICU environment as an element to be integrated into nursing care, through actions welcoming, helping them to cope with hospitalization of a relativein a critical unit.

D escriptors: Intensive care units. F amily. E motions. F amily nursing.

T itle: Family in the waiting room of an intensive care unit: revealed feelings.

\footnotetext{
${ }^{a}$ Extraído da dissertação de M estrado apresentada em 2010 ao Programa de Pós-G raduação em E nfermagem da U niversidade Federal de Santa Catarina (UF SC).

${ }^{b}$ M estre em Enfermagem, Professora do Curso de Enfermagem da U niversidade do Estado de Santa Catarina (UDESC), Enfermeira do Hospital Regional do Oeste (HRO), F lorianópolis, Santa Catarina, Brasil.

' D outora em Enfermagem, Professora A djunta IV do D epartamento de Enfermagem da UF SC, F lorianópolis, Santa Catarina, Brasil.

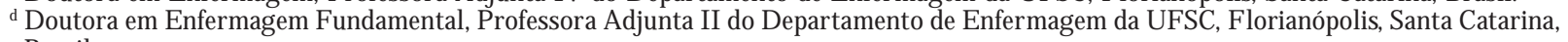
Brasil.

D outora em Enfer magem, Enfermeira do H ospital U niversitário Polydoro Ernani de São T hiago da U F SC, F lorianópolis, Santa Catarina, Brasil.
} 


\section{INT RODUÇÃO}

A hospitalização de uma pessoa em uma U nidade de Terapia Intensiva (UTI) éum momento geralmente difícil para a família, que pode experimentar diferentes sentimentos que envolvem não somente 0 seu familiar hospitalizado como também as suas perspectivas de vida(1).

A família é de vital importância nas questões referentes ao processo saúde/ doença do seu familiar. Quando uma pessoa, por diferentes motivos, necessita hospitalizar-se, numa UTI , o que ocorre é a ruptura da rede familiar. N este ambiente crítico, a separação do doente de sua família é praticamente imposta pelas circunstâncias criadas pela inter nação e por rotinas de visitas, muitas vezes rígidas, que fazem com que seus entes queridos mantenham-se muito distantes ${ }^{(2)}$.

E $m$ situação de risco de morte, a família é exposta a uma série de sentimentos, como a culpa pelo desejo e necessidade de deixar a vida prosseguir de modo mais habitual possível, pela irritação de algumas privações inevitáveis, pelo desejo, de maneira velada, de que o doente morra, para que a sobrecarga e o seu sofrimento frente à doença grave sejam aliviados, e até mesmo pela censura da sua necessidade de espairecer ${ }^{(3)}$.

A troca mútua e constante de sentimentos, realizada na vida familiar, condiciona-se a idéia de que sempre teremos próximo, alguém que nos possa confortar quando assim precisarmos e nos estimular quando nos sentirmos frágeis diante dos acontecimentos inesperados como uma doença aguda e uma inter nação em UTI.

$\mathrm{N}$ esta perspectiva, quando um indivíduo é acometido por uma doença, todo o contexto familiar sofre diante das possibilidades de perda, do desconhecido e do momento incerto(3).

A relação entre enfermagem e família deve ter por objetivo o seu bem-estar. A relação deve propiciar à família perceber na enfermagem as possibilidades de ajuda e de suporte. A enfermagem deve ser acessível, perceptiva, disponível e preparada para atender às necessidades referidas pelos familiares, relacionadas à experiência com a internação em ambiente crítico. Espera-se uma enfermagem que perceba a família também como foco do cuidado e não como apêndice do seu familiar doente.

Pelo fato de se conviver com a possibilidade da morte e da ruptura da família, diferentes sen- timentos e reações distintas ocorrem no ambiente familiar durante o período vivido. É importante ressaltar que a equipe de enfermagem deve conhecer as necessidades do familiar e a sua forma de enfrentar a hospitalização, para individualizar os cui$\operatorname{dados}^{(4)}$.

A forma de a família ver a enfermidade pode ser influenciada por fatores tais como: o estágio da vida familiar; o papel desempenhado pela pessoa enferma no lar; as implicações que o impacto da doença causa em cada indivíduo; e o modo como ela se organiza durante o período de doença ${ }^{(5)}$. 0 conhecimento desses fatores também é importante no cuidado ao familiar.

No momento da hospitalização e do processo de permanência na UTI, a enfer magem, ao realizar 0 acolhimento ao familiar, permite que 0 encontro se estabeleça e o diálogo ocorra. 0 estar presente, o relacionar-se, a criação de vínculo entre familiar/ enfermagem são formas de se estabelecer as relações de acolhimento.

Reorganizar o cenário de trabalho cujas ações ainda estão centradas no modelo tecnicista e voltadas, quase que exclusivamente, para a pessoa inter nada, desconsiderando o seu familiar, é um trabalho árduo e um desafio para a enfermagem, em especial a que atua em unidades de alta complexidade, como as UTIS.

E $m$ um estudo sobre o significado cultural do cuidado em UTI, as pesquisadoras observar am que o relacionamento da equipe de enfermagem com os familiares foi formal, burocrático e, sobretudo, despersonalizado. 0 diálogo com a família foi superficial, o enfermeiro estava ausente a maior parte do tempo, e os demais funcionários da unidade evitavam o contato com os familiares ${ }^{(6)}$.

A dificuldade de relacionamento entre a enfermagem e a família induz ao distanciamento. Esse ocorre por vários fatores, os mais evidentes referem-se à falta de preparo da enfermagem frente às necessidades da família e à organização do trabalho. Para alguns enfermeiros, a dificuldade em atender à família está vinculada às especificidades de uma terapia intensiva, às próprias limitações pessoais ou da equipe de saúde e, ainda, ao modo das famílias expressarem seus sentimentos ${ }^{(7)}$.

0 cuidado de enfermagem na UTI vai além de consentir ou não a visita do familiar, compreende também o estabelecimento de uma relação de confiança e de auxílio. A equipe de enfermagem tem a função de identificar as reais necessidades 
dos familiares. Quanto mais antecipada for a inter ação enfer meiro/ família, melhor será para os familiares e, consequentemente, para o paciente hospitalizado(6).

Estudos apontam a necessidade de atender à família antes da sua entrada na UTI, para poder prepará-la para o encontro com seu familiar doente $\mathrm{e}^{(2,6,8,9)}$

A prática assistencial em UTI mostra que é incontestável a necessidade de atender aos familiares, tendo em vista os seus sentimentos e as suas fragilidades. É preocupante notar que, na maioria das vezes, o visitante seja abordado de forma sutil pelos enfermeiros. N estesentido, tem-se como pressuposto que, se os profissionais tiverem a oportunidade de identificar o sentimento do familiar em UTI, suas práticas de cuidado estarão alicerçadas no respeito das necessidades emocionais dos sujeitos envolvidos.

Diante deste contexto, foi proposto como pergunta norteadora de pesquisa: Como os familiares identificam os seus sentimentos antes de entrarem no ambiente de terapia intensiva?

Para responder ao questionamento e procurando minimizar a lacuna que existe nesta área, com relação aos sentimentos revelados, foi traçado como objetivo desta investigação: conhecer quais os sentimentos dos familiares de pacientes internados na UTI antes da visita.

\section{MET ODOLOGIA}

Trata-se de uma pesquisa qualitativa, exploratória e descritiva, realizada com os familiares de pacientes internados na UTI geral de um hospital público de grande porte, referência da região oeste do estado de Santa Catarina.

0 número de participantes foi determinado a partir da necessidade de informações. U m princípio orientador da quantidade de participantes foi a saturação dos dados ou informações, isto é, amostrar até o ponto em que não é obtida nenhuma infor mação nova e é atingida a redundância(10). Participaram do estudo 18 familiares.

Os critérios de inclusão foram: ter idade igual ou superior a 18 anos; ter um familiar internado na UTI num período mínimo de quarenta e oito horas; ter relações de convívio frequente/ diário com o paciente internado; ter laços consanguíneos ou de afetividade com o paciente; e aceitar participar da pesquisa.
Vale ressaltar que no cotidiano da UTI, onde este estudo foi realizado, o mais comum é a visita ser realizada pelas pessoas que compõem a família nuclear do paciente internado. São principalmente filhos, filhas e esposas ou esposos. A escolha de qual membro da família participaria da entrevista se dava entre os familiares, que utilizavam como critério o que visitava com mais frequência o familiar doente e que tinha mais facilidade de comunicação verbal.

A pesquisa foi aprovada pelo Comitê de Ética em Pesquisa com Seres Humanos da U niversidade Federal de Santa Catarina (Protocolo no 083/ 09), seguindo as recomendações da Resolução 196/ 96 do Consel ho $\mathrm{N}$ acional de Saúde ${ }^{(11)}$.

Para a coleta de dados foi explicado aos participantes, na sala de espera da UTI, o objetivo da pesquisa e consultado o interesse em participar, obtendo assim a assinatura do Termo de Consentimento Livre e Esclarecido. A coleta ocorreu nos meses de junho e julho de 2009, através de entrevista semiestruturada. Os familiares foram questionados, individualmente, sobre quais eram os seus sentimentos, naquele momento, em que aguardavam na sala de espera da UTI, para realizar a visita ao seu familiar.

As entrevistas foram agendadas previamente e realizadas na sala de supervisão cedida pela gerência de enfermagem, que era um ambiente privativo e próximo da unidade. Foram gravadas em formato M P3, com a duração média de trinta minutos e transcritas posteriormente. Para preservar a privacidade dos sujeitos do estudo, utilizouse para identificação o código por numeração de ordem de execução, por exemplo: Familiar 1 (F 1), Familiar 2 (F 2).

Para o tratamento dos dados, adotou-se três figuras metodológicas do Discurso do Sujeito Coletivo (DSC): Expressões Chaves (ECH s), as I deias Centrais (ICS) e o Discurso do Sujeito Coletivo (DSC) $^{(12)}$.

As ECH s são pedaços, trechos ou transcrições contínuas ou descontínuas da fala que revelam a essência do conteúdo de um dado fragmento que compõe o discurso. Devem ser destacadas pelo pesquisador, e revelam a essência do depoimento ou, mais precisamente, do conteúdo discursivo dos segmentos em que se divide o depoimento. As ICs são expressões linguísticas que revelam ou descrevem de maneira mais sintética e precisa possível o sentido, ou o sentido e o tema, de cada conjun- 
to homogêneo de ECH s e que vão dar origem ao DSC(12).

Portanto, o DSC é uma agregação, ou soma não matemática de pedaços isolados de depoimentos, de modo a formar um todo discursivo coerente, em que cada uma das partes se reconheça como constituinte desse todo. É um discurso síntese redigido na primeira pessoa do singular e composto pela "colagem" das ECH s que têm a mesma IC (12).

\section{RESULTADOSE DISCUSSÃO}

Os resultados aqui apresentados e discutidos baseiam-se na vivência de 18 familiares. D estes, 15 eram mulheres, sendo que nove eram filhas, duas esposas, duas mães, uma nora e uma irmã. A faixa etária variou de 23 a 55 anos. A média de permanência do familiar hospital izado foi de cinco dias e, quanto ao grau de instrução, prevaleceu o ensino primário completo.

Cabe contextualizar que, como rotina, a entrada dos familiares no hospital, ocorre cinco minutos antes de começar a visita na UTI, que diariamente possui dois horários: um ao meio dia e outro às 18 horas. Os visitantes aguardam o horário para entrar, conforme a autorização de um membro da equipe de enfer magem previamente escalado, e que faz a chamada de dois membros da família pelo nome do paciente internado, permitindo ficarem ao lado do leito por 30 minutos.

Os depoimentos dos familiares traduziram dois temas: sentimentos dos familiares relacionados à hospitalização na UTI e sentimentos durante a espera para entrar na UTI.

\section{T ema 1: Sentimentos relacionados à hospitalização na UT I}

Os sentimentos decorrentes da inter nação e permanência do familiar na UTI estão no discurso representado pela dor, tristeza, angústia, impotência, medo e desespero, ocasionado por um grande impacto emocional e pela angústia ante ao incerto ou à possibilidade iminente da perda.

IC 1: O sfamiliares referem sentimentos negativos, como dor, tristeza, angústia, impotência, medo e desespero.

DSC 1: N unca imaginei ter um familiar internado na UTI, éhor rível, muita dor, éum momento muito difícil, onde os sentimentos emergem numa intensidade que vai da tristeza pelo afastamento do convívio com os seus, angústia pela gravidade da doença, levando a impotência, medo e ao desespero, pois não podemos fazer nada. $N$ estes momentos a gente descobre que amar é uma das melhores coisas da vida, porque neste momento percebemos que somos humanos, que trocaríamos tudo para ficar perto, pegar na mão, dar um abraço (F 1, F 3, F 4, F5, F6, F 8, F9, F 10, F 13, F17, F 18).

A inter nação na UTI é considerada um momento muito difícil, que se instala e interfere no equilíbrio familiar. É um período marcado por sofrimentos e que mobiliza sentimentos diversos como os relatos pelos familiares deste estudo.

Entende-se que os sentimentos gerados nos familiares pela internação do seu ente nesse tipo de setor intensificam-se pela impotência de Ihe garantir um convívio contínuo. 0 acompanhante considera injusta esta separação e espera que os profissionais de saúde repensem e passem a valorizar a sua contribuição.

E $m$ relação a esses sentimentos, outros estudos também apontaram o medo do desconhecido, da morte, do isolamento e da ansiedade ${ }^{(7,13)}$. No momento em que o familiar passa a vivenciar sentimentos próprios de quem tem um familiar hospital izado na UTI, percebe-se a sua fragilidade e as suas necessidades.

Para atender o familiar como pessoa, que expressam sentimentos como tristeza, impotência, desespero e angústia, os profissionais de enfer magem precisam colocar-se no lugar deles; precisam ter empatia pelo outro, com o seu sofrimento. "Precisamos entrar no seu mundo perceptual, examiná-lo, senti-lo, compreendê-lo sem críticas ou julgamento e voltar para o nosso lugar e, deste, poder ajudá-Io da melhor maneira possível"(14,15).

O DSC 1 denota que a família sente que esse seu papel de alicerce, de ponto de apoio, encontrase afetado com a inter nação. Para a família, ao menor sinal de que al go saiu do contexto da normalidade, do aceitável, emerge um turbilhão de sentimentos.

A família se preocupa com o paciente e vivencia o medo e a insegurança, muitas vezes, resultado da incerteza em relação à conduta e ao tratamento. Sendo o paciente o foco do cuidado, as necessidades dos familiares são, muitas vezes, desconsideradas pela equipe de enfer magem. A sensibilidade do enfermeiro em perceber as necessidades da família pode resultar na implementação de novas políticas, como horário de visitas mais flexível, 
maior proximidade da equipe de enfermagem e maior facilidade na obtenção de infor mações ${ }^{(6)}$.

Acredita-se que o familiar vivencia o sentimento do medo por ele estar com al guém próximo de si, a quem ele quer bem, inter nado na UTI, setor que carrega o mito de este ser um lugar para morrer. A morte não é certa, porém estar vivendo esta expectativa de perda traz o medo para sua experiência de vida; mesmo sendo apenas uma expectativa, não afasta a presença do medo.

Neste contexto, a partir da identificação da vulnerabilidade da família, é possível sistematizar a assistência de enfermagem para ela, que poderá favorecer as mudanças que consideramos fundamentais para o alcance do seu fortal ecimento. Porém, é preciso destacar que a vulnerabilidade é um sentimento dinâmico e contínuo, com momentos de alternância em relação às consequências (14-17).

Cabe salientar que, dur ante a col eta de dados, muitos familiares apresentavam dificuldades em expressar verbalmente seus sentimentos, apresentando muitos momentos de choro frente à situação vivenciada.

\section{T ema 2: Sentimentos durante a espera para entrar na UT I}

No discurso encontra-se rel atado o difícil momento por que passa o familiar enquanto aguarda a entrada na UTI.

IC 2: 0 momento antes da visita na UTI é de muita ansi edade, dúvida, angustia e de expectativa infinita.

D SC2: E sse momento é o pior do dia, pois ficamos ansiosos, angustiados, não vendo a hora de entrar, de ver como o familiar se encontra, se está acordado, se está falando, se está bem. E sperar na porta por cinco minutos é como se fosse uma hora, porque se atrasa um pouquinho, fica um silêncio, todo mundo começa a bater 0 pé, mexer com as mãos, anda de um lado para 0 outro. $\mathrm{N}$ a entrada, a expectativa éinfinita, mas a emoção toma conta, temos que ser forte para continuar e dar força aos demais (F 2, F 4, F 7, F 8, F 11, F 12, F 14, F 15, F 16).

0 momento de ansiedade vivido pelos familiares deste estudo, enquanto aguardavam a entrada na UTI foi também encontrado em outros estudos $^{(18,19)}$. A Ansiedade é uma reação normal ao estresse e ocorre geralmente quando um indivíduo enfrenta uma mudança ou a necessidade de agir de modo diferente do habitual| ${ }^{(19,20)}$.
Estudos abordam a necessidade de assistência e acolhimento às famílias dos pacientes internados na UTI, que per manecem nas sal as de espera. U m aspecto destacado foi a pouca orientação que os familiar es recebem. Portanto estes resultados evidenciam o descaso de muitos profissionais da equipe da UTI com relação à atenção ao familiar, desconsiderando que precisam ser atendidos em suas necessidades, em especial a de informação e de escuta, merecendo do profissional atenção e apoio(2,6-8).

A falta de assistência e acolhimento, na realidade em que este estudo foi realizado, é ag ravada pela falta de um local privativo para conver sar com os familiares, pois a sala de espera da UT I é compartilhada com os familiares dos pacientes do Centro Cirúrgico e da U TI neonatal, além de ser próxima do corredor de acesso às mesmas unidades, sendo, portanto, um local movimentado e de trânsito constante de pessoas.

E stabelecer vínculo enfermagem/ família é uma forma de amenizar o isolamento social que a hospitalização acomete, bem como auxiliar na reestruturação biopsicossocial da família. Agir perante a família de forma a ajudá-la em seus anseios não devem dificultar o cotidiano do trabal ho da equipe de enfermagem, que geralmente alega a falta de tempo para atender aos familiares ${ }^{(2)}$.

E ntre os fatores que dificultam esses processos de integ ração e vínculo, está o desconhecimento por parte da equipe de enfermagem frente ao modo de ser e de perceber dos familiares ${ }^{(6)}$. Está em poder da enfermagem, enquanto profissão que enfatiza o tratamento personalizado e holístico, realizar as ações que poderiam viabilizar o entendimento e a compreensão da inter nação em UTI, tanto por parte dos sujeitos nela inter nados quanto de seus familiares.

É essencial o acompanhamento do familiar, pela enfermagem, durante a inter nação, principalmente no momento da primeira visita ao seu familiar hospitalizado, para Ihe prestar apoio e orientação no que for necessário, al ém do que essa atitude poderá minimizar a visão de unidade hosti|(15,17,21).

Recomenda-se um partilhar de experiências entre os familiares, nesta sala de espera, acreditando que neste momento pode-se revelar um sistema de cooper ação, que propiciará o apoio necessário para superar parte das dificuldades de estarem vivendo a internação de um ente querido na UTI. 
Este sistema de cooper ação estabelecido entre as famílias que vivenciam a dor pode ser um exemplo a ser seguido pelos enfermeiros, que, por vezes, esquecem de ser solidários até com os próprios colegas que precisam de ajuda. 0 sentimento de solidariedade presente em muitas das relações entre as famílias dos clientes em estado crítico, na sala de espera, devem servir para nortear as relações de trabalho e as relações com as famílias que tanto precisam de apoio.

No entanto, essa abertura à família é frágil, talvez em virtude, dentre outros fatores, do pouco preparo dos trabalhadores que atuam nas UTIS para 0 atendimento a essa clientela de familiares, al iado à rotina complexa destas unidades, que muitas vezes faz com que os profissionais da saúde ignorem ou deixem de utilizar em suas ações atos como o tocar, conversar, ouvir, em detrimento da demanda de atividades que necessitam realizar. E spera-se que esta realidade encontrada possa ser sanada, ou ao menos atenuada.

\section{CONSIDERAÇÕES FINAIS}

Os Discursos do Sujeito Coletivo revelaram um emaranhado de sentimentos com os quais os familiares convivem em seu dia a dia, durante a hospitalização de seu parente na UTI e em especial no momento que antecede a visita. D os sentimentos revelados destacam-se a angústia, o medo, a impotência e a tristeza.

Acredita-se que esses sentimentos seriam minimizados se o espaço da sala de espera fosse ocupado por multiprofissionais da saúde, em especial enfermeiros, que oferecessem 0 acol himento a esses familiares, preparando-os para a visita ao seu familiar internado, escutando-os e esclarecendo dúvidas, atendendo às suas necessidades.

Contudo, entende-se que isso requer, além de uma estrutura física que ofereça conforto e privacidade aos familiares, sensibilização, preparo, reconhecimento e val orização dos sentimentos e necessidade dos familiares pelos gestores e demais profissionais que atuam em unidades críticas.

Ressalta-se que este estudo veio corroborar com vários outros, al guns aqui citados, sobre a necessidade de se incluir o familiar como sujeito do cuidado da equipe da UTI. N esse sentido, almejase que, no lado de fora e dentro da UTI, ocorram ações acolhedoras para os familiares, ajudando-os a enfrentar a hospitalização de um familiar na unidade crítica.
Espera-se que esses resultados possam auxiliar na capacitação dos profissionais para 0 acoIhimento à família e para a inserção desta no ambiente da UTI como elemento a ser integrado no cuidado.

\section{REFERÊNCIAS}

1 F rizon G. Os familiares na sala de espera de uma unidade de terapia intensiva: sentimentos revel ados e expectativas de cuidado [ dissertação] . Florianópolis: U niversidade F ederal de Santa Catarina; 2009.

2 Nascimento ERP. A colhimento no espaço das relações na U nidade de Terapia I ntensiva [ tese] F lorianópolis: U niver sidade Feder al de Santa Catarina; 2003.

3 M otta M G 0.0 entrelaçar de mundos: família e hospital. In: Elsen I, M arcon SS, Santos M R, organizadores. 0 viver em família e sua interface com a saúde e a doença. 2ae ed. M aringá: E duem; 2004. p. 153-67.

4 Boehs AE. A nálise dos conceitos de negociação/ acomodação da teoria de M. L eininger. Rev Latino-Am Enfermagem. 2002;10(1):90-6.

5 Soares M . Cuidando da família de pacientes em situação de terminal idade internados na U nidade de T erapia Intensiva. Rev Bras T er Intensiva. 2007;19(4):4814.

$6 \mathrm{M}$ aruiti M R, G aldeano LE. N ecessidades de familiares de pacientes inter nados em unidade de cuidados intensivos. Acta Paul Enferm. 2007;20(1):37-43.

7 Corrêa AK, Sales CA , L uciana S. A família do paciente internado em terapia intensiva: concepções do enfermeiro. Acta Scientiarum. 2002;24(3):811-8.

8 G otardo G I B, Silva CA 0 cuidado dispensado aos familiares na unidade de terapia intensiva. Rev E nferm UERJ. 2005;13:223-8.

9 F reita KS. Necessidade de família em unidade de terapia intensiva: análise comparativa entre hospital público e privado [ dissertação]. São Paulo: E scola de Enfermagem, U niversidade de São Paulo; 2005.

10 M inayo M CS. 0 desafio do conhecimento: pesquisa qualitativa em saúde. São Paulo: Hucitec/ Abrasco; 2010.

11 M inistério da Saúde (BR), Consel ho N acional de Saúde, Comitê N acional de Ética em Pesquisa em Seres H umanos. Resolução 196, de 10 de outubro de 1996: 
diretrizes e normas regulamentadoras de pesquisa envolvendo seres humanos. Brasília (DF); 1996.

12 L efèvre F, L efèvre AM C. 0 discurso do sujeito coletivo: uma nova abordagem metodológica em pesquisa qualitativa. Caxias do Sul: EDU CS; 2005.

13 Lemos RCA, Rossi LA. 0 significado cultural atribuído ao centro de terapia intensiva por clientes e seus familiares: um elo entre a beira do abismo e a liberdade Rev Latino-Am Enfermagem. 2002;10(2): 345-57.

14 Pettengill M A M, Angelo M. Vulnerabilidade da família: desenvolvimento do conceito. Rev Latino-Am Enfermagem. 2005;13(6):982-8.

15 M atsuda LM, Victor ACS, É vora Y D M, M ello GARN. A comunicação verbal da equipe de enfermagem de uma UT I-adulto durante o proces-so de visita: perspectiva dos visitantes. In: A nais do $8^{\circ}$ Simpósio Brasileiro de Comunicação em Enfermagem; 2002 M ay 02-03; São Paulo, Brasil. São Paulo: Escola de E nfer magem de Ribeirão Preto, U niversidade de São Paulo; 2002.

16 Prochnow AG, Santos JL G, Pradebon V M , Schimith $M D$. A colhimento no âmbito hospitalar: perspecti- vas dos acompanhantes de pacientes hospitalizados. Rev G aúcha Enferm. 2009;30 (1):11-8.

17 Comassetto I, Enders BC. Fenômeno vivido por familiares de pacientes inter nados em U nidade de $\mathrm{Te}$ rapia Intensiva. Rev G aúcha E nferm. 2009; 30(1):4653.

18 Beccaria LM, Ribeiro R, Souza GL, Scarpetti N, Contrin LM , Pereira RAM, et al. Visita em U nidade de Ter apia Intensiva: concepções dos familiares quanto à humanização do atendimento. Arq Ciênc Saúde. 2008;2(15):65-9.

19 Almeida AS, Aragão NRO, M oura E, Lima GC, Hora EC, Silva LASM. Sentimentos dos familiares em relação ao paciente internado em unidade de terapia intensiva. Rev Bras Enferm. 2009;62(6): 844-9.

20 Bettinelli LA, E rdmann AL. Internação em U nidade de Terapia Intensiva e a família: perspectiva de cuidado. Av Enferm. 2009;27(1):15-21.

21 Dezorzi LW, Camponogara S, Vieira DF VB. 0 enfermeiro de terapia intensiva e o cuidado centrado na família: uma proposta de sensibilização. Rev $\mathrm{G}$ aúcha Enferm. 2002;23(1):84-102.

\author{
E ndereço da autora / Dirección del autor / \\ Author's address: \\ Kátia Cilene G odinho Bertoncello \\ Rua H ipólito M afra, 203, ap. 307ą, E difício M ir anteSul, \\ Saco dos Limões \\ 88045-410, Florianópolis, SC \\ E-mail: kbertoncello@yahoo.com.br
}

Recebido em: 24/ 10/ 2010

A provado em: 13/ 02/ 2011 